Nació en Temuco, Chile, y es sobrino-nieto del poeta Pablo Neruda, a cuyo entorno dedicó el ensayo Retrato de familia (Neruda 1904-1920). Es también autor del Álbum de Teтисо, que contiene una relevante colección fotográfica de la juventud del poeta. Comenzó a dar a conocer su poesía en 1978 y ha publicado varios libros de poesía entre los que destacan Pájaros de contrasueño, Karmazul. Para duendes y sirenas y Carta para un hijo imaginario y otras desmemorias. Desde 1994 hasta 2001 ha sido el Coordinador General del "Tren de la Poesía", que es la denominación con que se agrupan una serie de actos de homenaje para conmemorar la muerte de Pablo Neruda, en la ciudad de Temuco y en otros lugares de la región.

\title{
LA SOLEDAD SIN MÁRGENES
}

\author{
BERNARDO REYES
}

\section{PIDO SILENCIO}

Abora me dejen tranquilo.

Ahora se acostumbren sin mí.

Yo voy a cerrar los ojos.

$Y$ sólo quiero cinco cosas,

cinco raíces preferidas.

Una es el amor sin fin.

Lo segundo es ver el otoño.

No puedo ser sin que las bojas vuelen y vuelvan a la tierra.

Lo tercero es el grave invierno, la lluvia que amé, la caricia del fuego en el frío silvestre.

En cuarto lugar el verano redondo como una sandía.

La quinta cosa son tus ojos. Matilde mía, bienamada, no quiero dormir sin tus ojos, no quiero ser sin que me mires: yo cambio la primavera por que tú me sigas mirando.

Amigos, eso es cuanto quiero.

Es casi nada y casi todo.

Abora si quieren se vayan.

He vivido tanto que un día tendrán que olvidarme por fuerza, borrándome de la pizarra: mi corazón fue interminable.
Pero porque pido silencio

no crean que voy a morirme:

me pasa lo contrario:

sucede que voy a vivirme.

Sucede que soy y que sigo.

No será pues que adentro de mícrecerán cereales, primero los granos que rompen la tierra para ver la luz, pero la madre tierra es oscura: $y$ adentro de mí soy oscuro: soy como un pozo en cuyas aguas la noche deja sus estrellas $y$ sigue sola por el campo.

Se trata de que tanto be vivido que quiero vivir otro tanto.

Nunca me sentí tan sonoro, nunca be tenido tantos besos.

Abora, como siempre, es temprano. Vuela la luz con sus abejas.

Déjenme solo con el día. Pido permiso para nacer.

(Pablo Neruda, del libro «Estravagario»)

Amigas y amigos:

Quiero hablarles de silencios y soledades. En específico de una soledad sin márgenes, que ya es casi un lugar común en el estudio de la lírica nerudiana y que de un modo u otro evocan otras soledades como la de Miguel Hernández, ya sea en sus procesos creativos como cuando tiene que vivir sus encarcela- 
mientos que hasta hoy son lecciones de luz y de esperanza para la condición humana.

$\mathrm{Y}$ decirles también que es un honor enorme poder estar justo hoy conmemorando este 28 de marzo, en que con treinta y un años Miguel parte a encontarse con su muerte anunciada.

Quizás el poeta de Orihuela no se imaginó siendo protagonista de una celebración llena de vida y de alegría, que no hace sino reafirmar nuestras convicciones humanistas y poéticas en el legado de estos dos amigos, de estos dos hermanos mayores que nos están señalando un camino inequívoco del renacer desde la muerte.

Indagar en la estructura familiar, en las raíces que conforman el sostenimiento de la existencia, como quien busca una dirección en una ciudad desconocida, parece ser lo único razonable cuando se ha perdido el sentido de todo.

Éramos jóvenes, se construía por aquél tiempo en nuestra patria lo que sería una sociedad solidaria y socialista, no obstante que en nuestras universidades el ceño hosco, el discurso nacionalista recordando películas del horror nazi, eran el pan de cada día.

Algunos no alcanzamos a comprender, por falta de tiempo o por incapacidad, todo el proceso que volvió turbulenta nuestra historia.

Y luego el incendio que estalla, la muerte y la tortura para tantos, y para los mas afortunados, la mordaza y la afasia. El grito impotente implotando como un volcán inverso.

De un día para otro pasamos a ser los protagonistas de una comedia en que un grupo de actores agredían, allanaban casas y quemaban libros de verdad: el lugar común de la dictadura que no sólo se conoció en el mundo por la quema de la palabra escrita, sino llegó a su apogeo con la quema de personas vivas, como fue lo ocurrido con los estudiantes Rodrigo Rojas Denegri y Carmen Quintana, quemados por una patrulla militar en las calles de Santiago, en un incidente todavía no aclarado del todo.

$Y$ entre quema y quema, entre saqueo y saqueo, le llegó su turno a las casas del poeta Pablo Neruda. Su fallecimiento, a escasos días del golpe, quedó registrado en la memoria colectiva como un símbolo trágico de la tristeza que aniquilaba toda expresión de utopías por realizar.

Y si para todos los chilenos la noticia fue bastante brutal, para mis padres, para mi familia, fue escalofriante. Recuerdo a mis padres cruzando nerviosos la barrera militar an- tes de abordar el avión en Temuco con destino a Santiago, dándonos unas absurdas recomendaciones temblorosas: el funeral de Neruda, como es sabido, se convirtió en el primer acto de la resistencia chilena.

Después de transcurrido un tiempo impreciso, y coincidiendo con el despertar de nuestra patria que ya empeza-

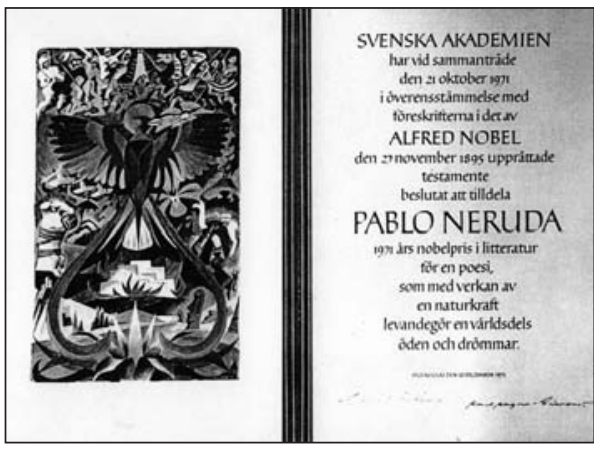

Diploma del Nobel. ba a recomponerse del saqueo y la demencia, Matilde, su viuda, sacaba fuerzas de flaquezas para reconstruir casas y sueños.

Desde Temuco viajaba yo para acompañarla en los homenajes que el pueblo de Chile realizaba para recordar la muerte del poeta, en el Cementerio General de Santiago, cada 23 de septiembre, fecha en que además comienza la primavera.

Así, también puntualmente, llegaba la policía, obedeciendo las oscuras y siniestras fuerzas del tirano, para agredirnos y tomar presos a unos cuantos, que eran arrastrados entre las tumbas del patio 29 , donde posteriormente fueran encontrados restos despedazados de cientos de detenidos desaparecidos.

No fue ni ha sido fácil asumir este papel de familiar del vate. Con mi mujer estuvimos años marginados de realizar cualquier labor productiva. Y desde otra perspectiva estaba el evidente conflicto de qué hacer con aquélla cantidad de sombra y de luz.

Resultó decisivo para mí, ver que en el proceso de la escritura, una parte del ser se aquietaba. Como cuando los ríos muestran los remansos y puede comprenderse, observarse mejor el fluir.

A la censura, a la prohibición de agruparse políticamente, se opuso entonces el texto poético, la palabra escrita registrando el proceso mental sobre el cual no existe ni existirá forma de acallamiento. Pertenezco pues a una generación de personas aplastadas por la dictadura militar, que tuvimos que sufrir el exilio en nuestras propias casas, en nuestro propio barrio, desde donde unos cuantos indeseables embriagados por el precario poder de las armas se refocilaban para mantenernos a raya: para mantenernos en silencio.

El final de esta historia es conocido: el grito enmudecido de un día para otro se materializó y no hubo fuerza en el mundo que pu-
La soledad sin márgenes BERNARDO REYES 


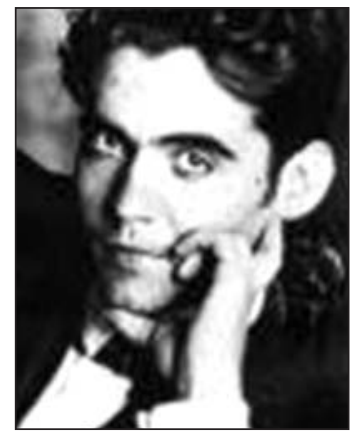

Federico García Lorca. diera acallarlo. Las manos se unieron y, con todas las deficiencias del caso, cierta expresión un poco coja de la democracia, comienza nuevamente a instaurarse en nuestra patria.

Correspondió este período al momento de los balances. De detenerse en la senda para reflexionar, para meditar.

Pero antes de racionalizar acerca de un proceso histórico, se comienza por mirar la estructura de las emociones, por volver la mirada sobre sí mismo.

La indagación en estos sueños y afectos tuvo un cuerpo físico. Se denominó Retrato de Familia, Neruda 1904-1920, ensayo que fuera publicado en su primera edición por una editorial puertorriqueña.

Se trataba en este libro de narrar acerca de una serie de antecedentes ignorados de mi propia estructura familiar y que de paso otorgaban una visión más exacta de uno de sus miembros.

Neruda es en este ensayo una especie de buen pretexto para contar una historia familiar. Porque eso es lo que todos somos: individuos que nos debemos a un todo mayor, a una familia que para bien o para mal transmitió por los conductos de la oralidad, ciertas pautas del misterio y de la luz que rodean todas las existencias.

La aparente inocencia de esta recopilación epistolar y fotográfica, pronto remecerían al mundo de la cultura cuando a partir de este mismo proceso de investigación, aparecieron los mas de 150 poemas inéditos, en un añejo atado de fotocopias, que componían la primera y adolescente obra, aún inédita, de Pablo Neruda, hoy ya editados y reeditados en muchos países. Este libro recibió el nombre de Cuadernos de Temuco y es considerado hasta la fecha como el hallazgo de mayor importancia literaria luego de la muerte del poeta.

Estudiosos de su obra, coleccionistas profesionales y curiosos consuetudinarios, agarrándose los cabellos habían buscado infructuosamente por años los cotizados manuscritos, rematados por un, hasta ahora, anónimo coleccionista en la afamada casa de remates Sotheby's, en Londres.

Fue, en cambio, una mirada de la familia hacia sí misma la que generó este valioso descubrimiento, acompañado de una perspectiva diferente a todo lo conocido en los estudios biográficos.

Si eventualmente estas investigaciones, estos viejos documentos, estas palabras, pueden ser útiles para mirar al mito desde la historia real, estoy cierto que esa misma mirada podrá fortalecer precisamente el mito de unificación que representa Neruda, este mito que soñara Bolívar, este mito y epopeya cotidiana que conforma nuestra ineludible raigambre cultural latina.

Casi aproximándose al fin de sus días $\mathrm{Ne}-$ ruda escribió lo siguiente:

Mi discurso será una larga travesía, un viaje mío por regiones lejanas y antípodas, no por eso menos semejantes al paisaje y a las soledades del norte. Hablo del extremo sur de mi pais...

Por alli, por aquellas extensiones de mi patria adonde me condujeron acontecimientos ya olvidados en sí mismos, hay que atravesar, tuve que atravesar los $A n$ des buscando la frontera de mi país con Argentina. Grandes bosques cubren como un tínel las regiones inaccesibles y como nuestro camino era oculto y vedado, aceptábamos tan sólo los signos más débiles de la orientación. No babia buellas, no existian senderos y con mis cuatro compañeros a caballo buscábamos en ondulante cabalgata -eliminando los obstáculos de poderosos árboles, imposibles rios, roquerios inmensos, desoladas nieves, adivinando más bien-el derrotero de mi propia libertad.

Los que me acompañaban conocían la orientación, la posibilidad entre los grandes follajes, pero para saberse más seguros montados en sus caballos marcaban de un machetazo aqui y allá las cortezas de los grandes árboles dejando buellas que los guiarían en el regreso, cuando me dejaron solo con mi destino.

Cada uno avanzaba embargado en aquella soledad sin márgenes, en aquél silencio verde y blanco, los árboles, las grandes enredaderas, el bumus depositado por centenares de años, los troncos semiderribados que de pronto eran una barrera más en nuestra marcha...

Este discurso esta larga travesía a la que se refería Neruda, es pronunciado en el momento que le es otorgado el Premio Nóbel en 1971, dos años antes de su muerte, donde el poeta centra sus recuerdos en el país de la memoria.

Es posible que haya sido de madrugada aquel jueves 24 de febrero de 1949, cuando un hombre perseguido y embargado por una soledad sin márgenes, cruzara a caballo la cordillera, clandestinamente, procedente de Chile.

En las horas del crepúsculo, en las ambiguas horas de la noche-día, se suelen tomar las decisiones que la ansiedad exige, máxime cuando se trataba de una persecución que ya se había prolongado por poco más de un año: desde el 5 de febrero de 1948 para ser precisos. Ese día, los Tribunales de Justicia de Chi- 
le habían ordenado su detención luego que el 3 de febrero la Corte Suprema aprobara el desafuero como senador debido al discurso leído el día 6 de enero del mismo año.

Toda la situación dejó estampada una huella profunda: los arrieros que lo guiaban rumbo a la libertad, danzando alrededor de una calavera de buey, trasmitían en un extraño rito, de desconocido a desconocido, la impronta de la continuidad y la fragilidad de la condición humana.

Allí, en medio de la espesa vegetación que dificultaba el desplazamiento, la solidaridad se manifestaba sin aspavientos y sin preguntas.

Los viajeros, luego de hundirse en unas cordilleranas e inaccesibles aguas termales que fluían de lo profundo -también con su cuota de misterio- en una suerte de bautismo ancestral, emprendían rumbo a su destino para no verse nunca más.

Por las descripciones, era un territorio sin fronteras, o más exactamente un territorio demarcado por los hitos del afecto: hombres sin documentación de uno y otro lado de la cordillera buscando días mejores, huyendo de la justicia o de sí mismos.

Gobernaba por aquel entonces en Chile un payaso de turno, que como tantos aprendices de tirano ya habían empezado a realizar sus primeros ejercicios, a prepararse para la crueldad y la prepotencia en gran escala, propios de las décadas posteriores.

Las razones esgrimidas para concretar el desafuero y la posterior orden de detención, habían sido originadas en las denuncias al mentado presidente de la República, cuyas cabriolas políticas fueron dignas de alguna comedia del absurdo y que el tiempo felizmente se ha encargado de convertir en ceniza arrastrada por la brisa amable del olvido.

El fugitivo era un hombre de mi región, de mi ciudad, cercano y distante a la estructura familiar, hermano menor de mi abuelo paterno.

Por todo el país la policía buscó al fugitivo, incluídos los hornos de la panadería de mi padre en Temuco, en un jocoso operativo de allanamiento llevado a cabo por la Policía de Investigaciones, cuyo Prefecto, para colmo de males, resultó ser un amigo de infancia de mi padre.

- Mira Raúl, hagamos las cosas fáciles y dime derechamente si tú tienes escondido al «viejo»- expresó el Prefecto a mi padre.
- Pero claro que yo lo escondo. Mira, ándate derechito a los hornos, ahí lo vas a encontrar, ya que justamente los tenemos apagados para hacerles el aseo- le respondió mi viejo.

Sin entender el chiste, el grupo de policías comandado por su prefecto se dirigió raudo a los hornos y alumbraron el interior con expectación, hasta que las carcajadas de mi

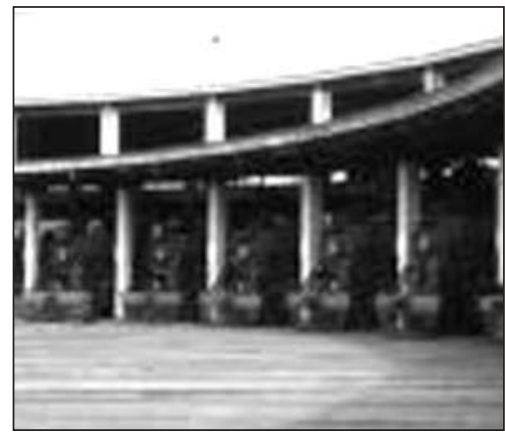

Maestranzas de Temuco. padre interrumpieron el operativo. Se trataba de dos hornos de ladrillos, bastante grandes, que perfectamente pudieron haber albergado a una docena de fugitivos. El detalle estaba en que demoraban varios días en enfriarse y cualquier mortal que hubiera buscado refugio, habría terminado deshidratado o chamuscado.

Avergonzado ante sus hombres, el Prefecto llamó hacia un costado a mi padre pidiéndole una ya inútil explicación.

- Tienes que ser muy huevón para pensar que el viejo iba a venir a esconderse en la casa de los parientes- machacó mi padre murmurándole al oído, y lo palmoteó amistosamente en la espalda.

Pasados los años, entre tantos relatos, escuchamos al tío Pablo referirse a su paso por Temuco, buscando escapar por el sur. Contaba que pasó en un automóvil frente a nuestra casa, que naturalmente estuvo vigilada por meses. Nos hablaba del enorme deseo que tuvo de haber pasado donde su «hueñi» Raúl, así le decía a mi padre. Sabía sin embargo que no podía detenerse, y no se detuvo.

Durante ese año de persecución, que obligaba como es sabido al cambio de domicilio permanente, Pablo Neruda termina de escribir su Canto General, la obra épica y mítica de mayor envergadura en nuestro idioma, al decir de los especialistas.

Se trata pues de hechos muy precisos. Se trata de un país, de una geografía, de una circunstancia con nombre y apellido.

No obstante cuando ocurre el acto de recordar, de sumirse en la estructura emocional, la memoria transfigura, difumina dichos acontecimientos, dejando en su reemplazo un sedimento de ternura, un pacto secreto sellado por miradas, por el pan y los abrazos com-
La soledad sin márgenes BERNARDO REYES 


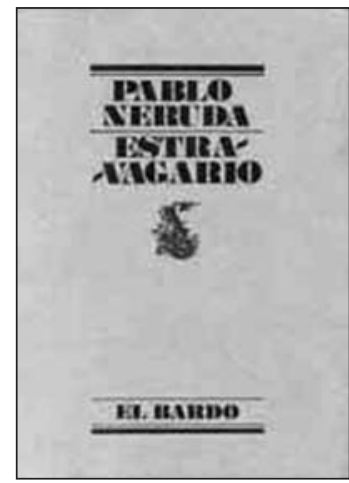

La soledad sin márgenes BERNARDO REYES partidos entre el calor de los leños ardiendo permanentemente en la cordillera agreste.

Es preciso recordar que esta evocación ocurre en un momento solemne: el 21 de octubre de 1971, con ocasión de la entrega del premio Nóbel de Literatura.

Ahora bien, este hombre sumido en aquella soledad sin márgenes, trasciende la circunstancia, sin omitirla, sin soslayarla, sino trasmutándola por la alquimia de las palabras en un lugar mítico.

Un amigo poeta mapuche me explicaba que para su pueblo nunca la frontera entre Chile y Argentina ha existido, pues ellos se han trasmitido por miles de años, de generación en generación, una demarcación cuya conceptualización geopolítica tiene que ver con el afecto del hombre con su entorno y su geografía, más que con líneas demarcatorias con líneas rojas, enseñadas en nuestros mapas.

En efecto, desde el avión, o parados en la misma frontera de nuestros países, la línea divisoria en la Cordillera de los Andes resulta ser una abstracción. Por lo menos eso es lo que nos trasmite la vegetación, las enormes montañas nevadas, el vuelo desmesurado de los cóndores.

Pero el tema éste de la relación del poeta con un sur mítico e histórico tiene sus raíces y es el caso explorarlas por cuanto es precisamente por estas palabras, por la poesía que brota de estas palabras, que gran parte del mundo toma conciencia de que el sur también existe.

Se inicia la saga cuando un muchachito de Temuco, por aquél entonces un pequeño pueblo de unos 10.000 habitantes, comienza a explorar los alrededores acompañando a su padre, el conductor don José del Carmen Reyes, en un tren que fue sinónimo de usurpación para los habitantes originarios de La Frontera -como era denominado el Territorio Mapuche- pero que para el poeta en ciernes constituye un bautismo de asombro.

Temuco -casi una aldea- recién se había fundado en 1881 como un fuerte militar, vale decir tenía unos treinta años.

Esta región, comprendida entre los ríos Bío-Bío por el norte y el Toltén por el sur, había sido denominada como La Frontera por los conquistadores por constituirse en un territorio inexpugnable de los indígenas mapuche, que resistieron el paso de los españoles por más de trescientos años.
Pero naturalmente un territorio segmentado y los ánimos exacerbados de las tropas chilenas victoriosas en la Guerra del Pacífico contra Perú y Bolivia, detonaron la decisión de poner fin a la Nación Mapuche: lo que no pudieron realizar por siglos los españoles, lo consumaron "patriotas chilenos» a fines del siglo antepasado, en una discutible y sangrienta campaña denominada «Pacificación de la Araucanía». Lo de Araucanía por Alonso de Ercilla. Lo de Pacificación, seguramente debió tratarse de alguna acepción semántica poco feliz.

Las ciudades del sur de Chile, como Temuco, eran generalmente fuertes militares ganados a punta de machetes a la selva virgen. A las avanzadas militares les seguía de cerca el tren que consolidaba definitivamente la victoria. Literalmente a la línea férrea se le hacía espacio penetrando en la selva virgen.

Neruda es considerado en todo el mundo como el poeta social por antonomasia. Sin embargo en todo este período en que vive en Temuco, hasta 1920, no existe ni un solo texto que le dedique a los vencidos de la gesta.

Avala lo que digo, el descubrimiento de los ya mencionados Cuadernos de Temuco, que es la única parte de su obra que permanecía inédita, redescubiertos hace pocos años, mientras realizaba la investigación de mi ensayo nerudiano al que me he referido también anteriormente.

Todos estos antecedentes inequívocos dan cuenta de un hombre, un joven, acorralado por circunstancias adversas: una familia que nada tiene que ver con la palabra escrita; un padre que se opone con violencia a cualquier manifestación artística; un clima que obliga al encierro y estimula la introspección.

Al mismo tiempo, estos antecedentes dan cuenta de un doble registro: por una parte el poeta se sume en lecturas, en los clásicos rusos entre otras, por insinuación de Gabriela Mistral que ejercía como directora de un liceo de niñas de Temuco, y por otro lado ocurre sin proponérselo, sin luchar, el registro realizado por los conductos de la intuición y el asombro: la vegetación embriagante, los pájaros, los insectos, la ternura del musgo y de la lluvia, son capaces de transmitir afectuosamente con su lenguaje milenario, un orden y una dimensión nunca vistas.

Es decir, coexisten una influencia cultural occidental dominante, incluída su simpatía por 
el anarquismo, proceso que pasa por la razón, y por otra parte una influencia cuyo proceso pasa por la intuición y que coincide con las raíces que nutren la cosmovisión de la cultura mapuche, cuyos ritos y ceremonias representaban y todavía representan valores diferentes a un orden occidental y cristiano que se quería imponer. Dicho sea de paso es el propio Neruda que da cuenta de esta dicotomía en dos textos anteriores al Canto General: Viaje al corazón de Quevedo y La copa de sangre.

Pudiéramos decir que el aprender a leer a los árboles y al oleaje marino, tuvo tanta o mayor incidencia que las lecturas literarias. Lo demuestra la enorme cantidad de referencias a esta región a lo largo de toda su vida, en textos de diversas etapas.

Lo dice de manera muy precisa el poeta Federico García Lorca, a la hora de presentar a Neruda en España: Neruda es un poeta más cerca de la sangre que de la tinta. Y tal vez más exactamente Gabriela Mistral cuando nos dice: Neruda es un místico de la materia.

Pero más que elucubrar sobre algunos antecedentes de su vida y su obra, que con toda seguridad muchos pueden manejar con mayor dominio, es ésta una contundente y amable invitación a pasar al living de una vieja casa, a un patio fragante que guardo en la memoria, insinuándoles que miren los colores del musgo y de la lluvia para dejar que sea simplemente la luz de un día cualquiera la que muestre las formas difuminadas en la oscuridad.

Nací en Temuco en una casa enorme que siempre se estuvo ampliando, a una cuadra de la estación de ferrocarriles.

Con mis hermanos nos íbamos a jugar al patio de la abuela pasando por una puerta interior que comunicaba con la propiedad de mis padres. Era un patio con fragantes lilas blancas, rosadas, moradas. En el centro había una palmera y una hendidura que atravesaba diagonalmente el sitio por donde me decían que antes se deslizaba un pequeño arroyo.

Había un hermoso palto que había crecido con su tronco torcido: entre sus afectuosas ramas solíamos refugiarnos con cualquier pretexto.

En el fondo del patio había un gran parrón que no daba uvas, pero sí una sombra amigable donde a veces almorzábamos los domingos, compartiendo el asado ritual, el vino, la alegría.

Me contaban que antes existió un palomar. Yo sólo conocía las hermosas casitas que mi hermano mayor les había hecho y al infame perro que las espantó y con el cual la única relación que tuve fue la presa escapando de sus fauces.

Mi abuela, separada tempranamente de mi abuelo paterno, casi siempre permanecía en su almacén, donde a veces nos íbamos a robarle dulce de membrillo. Se llamaba Almacén La Llave y tenía en efecto una enorme llave de madera, como muchos otros negocios y tiendas de Temuco, que también tenían inmensos objetos colgando en su entrada como emblemas para que los mapuche pudieran identificarlos, ya que ellos pertenecen a una cultura ágrafa, y que solo hace algunas décadas ha empezado a tener escritura.

Un día el hermano de mi abuelo, el tío Pablo, en uno de sus viajes al sur se la llevó y desde entonces está en su casa de Isla Negra.

Toda esta propiedad era de mis bisabuelos, luego heredada por los tres hermanos, Rodolfo, Pablo y Laura, para finalmente quedar en manos de mi padre y mi abuela.

Vale decir, cuando describo esta casa, sin mayores modificaciones que las necesarias para volverla a habitar después que un incendio se llevara el segundo piso, estoy describiendo una casa real, con personas reales que la habitaban y que se fueron muriendo y con las que conversábamos desde niños de parientes, gatos o palomas con toda naturalidad.

Hago hincapié en esta suma de obviedades por una razón muy simple: aquél hombre que en 1949 cruzó la cordillera, huyendo de la justicia - o de la injusticia- era el mismo hombre, el mismo familiar que habitó esta casa, donde después crecimos con mis hermanos. En esta casa no habían libros, apenas encontré unos viejos ejemplares de Salgari cuando se me ocurrió indagar un poco más de lo habitual.

$Y$ fue este hombre el que integra los trozos diseminados de su corazón en una sola unidad cuando descubre que él pertenece a este pobre pedazo de tierra austral tanto como cuando pone los pies en España y descubre que en la península Ibérica le cae en la frente y en el alma la sangre de sus heridas... de una base rocosa donde está temblando aún la cuna de la sangre.

Ya no será más el ausente de sí mismo, el que omite su propia constitución fragmenta$\mathrm{da}$ en un orden cultural dominante y lo que le dicta su corazón.

«Yo no aprendí en los libros ninguna receta para la composición de un poema, y no de-

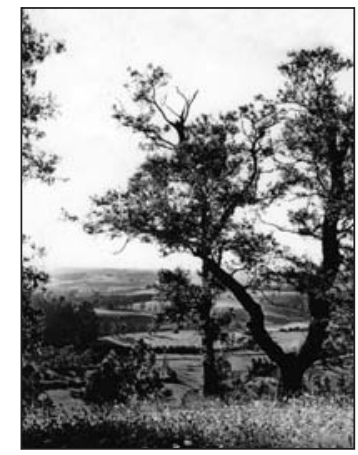

Tamuco desde el cerro Nielol.
La soledad sin márgenes BERNARDO REYES 


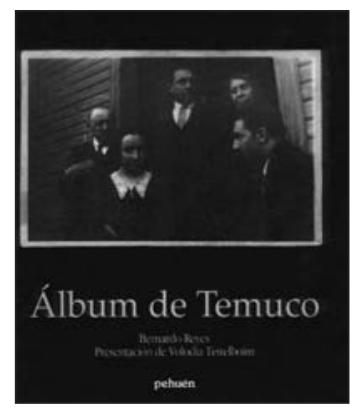

jaré impreso a mi vez ni siquiera un consejo, modo o estilo para que los nuevos poetas reciban de mí alguna gota de supuesta sabiduría», hace notar en el discurso de aquél día solemne cuando recibiera el Premio Nóbel de Literatura, luego de hacer un viaje al país de la memoria y remitirnos a la situación de fugitivo escapando por la cordillera.

De aquélla persistencia en el viaje, en el tránsito por mínimas huellas donde la condición humana se hace única en su diversidad, quedarían para la posteridad estas banderas de viento y sal, estos cantos de lluvia y follaje, con los que nos resulta fácil reencontrarnos en este breve espacio entre dos silencios.

Lo demás, claro está, pertenece al dominio de lo fosilizado o de lo decorativo como concepción de arte, y no estamos aquí para encenderle velitas a un santo, sino para celebrar la vida, o celebrar el triunfo de la vida.

Quisiera referirles un breve relato sucedido hace pocos años, el 24 de febrero de 1999 , en que se cumplían 50 años de aquélla memorable bofetada a un sistema represivo que no logró vencer la voluntad de una multitud de hombres y mujeres anónimos y solidarios de nuestra patria, que permitieron burlar la vigilancia policial por un año y luego permitir la huída del poeta.

Para esta conmemoración fuimos convocados quince escritores chilenos y quince escritores argentinos. La bella idea consistía en recorrer aquélla misma vieja senda por la selva y por la cordillera de los Andes, que atravesara el poeta a caballo.

En vez de caballos, poderosos vehículos con doble tracción nos encaramaron hasta donde se terminaba un camino que era algo más que una huella, hasta un oxidado hito metálico, señalando a Chile por un lado y Argentina por el otro, señalando la separación de las dos naciones hermanas. Por cierto no existía garita ni ninguna expresión de techumbre para guarecerse del frío y de la lluvia. En un rústico tablón eran timbrados nuestros pasaportes.

Los policías de ambas naciones se reían de nosotros, cuando caminábamos un paso en uno o en otro sentido. Es que en verdad las fronteras son más que nada una abstracción, o una especie de broma que unos cuantos se encargan de hacer parecer como una cosa seria e ineludible.

Mis convicciones nacionalistas palidecían La soledad sin márgenes BERNARDO REYES cuando me paraba con los pies abiertos fren- te al hito: en este caso estaba sencillamente en ambos países. Después supe que secretamente los gendarmes argentinos y los policías chilenos perdían su compostura militar cuando comparten en aquéllas desoladas tierras mas de lo que se admite oficialmente. Los fines de semana, dicen, suelen ser frecuentes los asados y los partidos de fútbol, los abrazos, el afecto.

Todavía en ese lugar no existe camino. Los vehículos nos dejaron frente a una huella y comenzamos a vivir exactamente lo que Neruda dijo en su discurso del Nóbel. Y lo que dijo era verdad.

Nuestras livianas mochilas, luego de algunas horas, milagrosamente habían duplicado su peso. A las canciones y los chistes del comienzo, le siguieron el silencio obligado, las palabras medidas que debían dosificarse para poder normalizar la respiración agitada por la larga caminata y la altura.

Honestamente creo que este encuentro binacional de poetas entre las ciudades de $\mathrm{Fu}$ trono (por el lado chileno) y San Martín de los Andes (por el lado argentino) ha sido uno de los más conmovedores actos a los que me ha tocado asistir.

Pero, en dónde radicaba la magia.

De regreso a mi país, navegando en una barcaza por el cordillerano lago Pirihueico, me sumí en una especie de fatiga o sopor, mezcla del cansancio natural y de ensoñación.

¿Eran verdad aquéllas islas pequeñas deshabitadas, cubiertas por una selva virgen impenetrable? ¿Aquéllos acantilados imposibles cubiertos de una vegetación espesa, aquéllas truchas de agua profunda, cazando mosquitos cerca de la embarcación, eran verdad?

¿Y el viento helado de la cordillera azotando en el rostro, era verdad?

$O$ todo no fue si no un sueño y todo lo aprendimos de boca de un poeta o del sueño repetido por otros.

En la semivigilia, recostado en la varanda de aquella barcaza, perfectamente pude -pudimos- haber sido los protagonistas de la vieja fábula oriental en donde un hombre que sueña a ser mariposa descubre en su sueño que tal vez es una mariposa soñando a ser hombre.

Porque de sueños somos y en sueños nos hemos de convertir.

Ocurre en el intertanto, que estas luciérnagas, que este aletear de aves en la noche rotunda, son simples señas de ningún camino, de un camino que jamás existirá, pero por cuya 
senda demarcada por la ternura, tendremos que seguir obligadamente.

Es por todas estas razones, en las que no existe sino el propósito de ser leal con el baúl de la memoria que hemos viajado tantos miles de kilómetros, dejando con ustedes el testimonio de esperanzas y fustraciones en las que se sostiene la condición humana, representadas en una familia común y corriente del sur del mundo.

Decía al comenzar estas palabras que estaba honrado de participar en este encuentro de estos dos hermanos mayores de la poesía universal. Por ello, en mi condición de poeta provinciano quisiera simplemente hacer un doble brindis por Miguel y por Pablo, leyéndoles dos poemas generados en una mirada a los míos, o dicho de otro modo, celebrando la poesía con mas poesía .

\section{RETRATO DE LUNA LLENA}

Está alegre mi padre

y me ha mirado a los ojos.

Azules ojos brillando,

iluminando a los míos.

Me ha pasado una bolsa de pólvora para cargar los cartuchos.

$\mathrm{Al}$ amanecer nuestros pies quebrarán la hierba escarchada y los perros cebados con la sangre de las aves muertas nos trasmitirán el presagio y la furia.

Me dirá que guarde silencio

y le sacará el seguro a su arma.

Los perros se quedarán quietos aguantando la respiración y tiritando.

Sentiré el corazón latir con fuerza.

Nuestros ojos se encontrarán.

Acerados ojos en un pacto con la muerte.

A lo lejos cantará una bandurria.

Los treiles temerosos aún no podrán con el frío.

Yo me quedaré atrás.

Los perros acezantes delante suyo.

Se llevará la escopeta al pecho y un trueno quedará vagando junto con las plumas arrastradas por el viento.
Yo correré tras los perros para quitarles la perdiz del hocico enrojecido

y un amasijo con olor a pólvora y sangre

llevaré a mi morral mientras comienza a amanecer.

Ahora mi padre es un puñado de musgo iluminado [por la luna.

Un puñado de musgo escarchado en el otoño cubriendo las hilachas

de su terno obscuro enredado en las raíces.

Un puñado de musgo que yo miro y que me mira mientras la luna se va diluyendo en las apacibles aguas del nuevo día.

\section{CARTA PARA UN HIJO IMAGINARIO}

Te escribo esta carta

sentado en la arena de un mar que no existe.

Cuando la leas,

sentirás el oleaje del planeta inventado,

las golondrinas cruzando el ocaso

y las gaviotas sin temor a la furia de las olas.

Un sol hermoso ilumina el sitio en donde habito:

una ventana inexistente

desde donde miro a los transeúntes escondido tras las [cortinas.

Desde esa ventana imaginaria

puedo reconocer tu rostro entre miles.

Podría ser el rostro mío que no conozco, perdido entre otros rostros perdidos que se encuentran sólo para desaparecer.

Pero, hijo querido, como tú no existes sino en mi [imaginación, y como tan lejano puedo ser desde tu inexistencia, puedes si lo deseas negar la sangre con que te he soñado.

Al fin apenas éstas son palabras lanzadas a una noche que empieza a crecer dentro de mí, pero que no existe: aunque brillen algunas estrellas como brillan las mínimas luces sobre una botella lanzada al mar por un naúfrago cansado ya de su soledad.

(De Bernardo Reyes, Carta para un bijo imaginario y otras desmemorias, Chile, Dolmen, 1996).

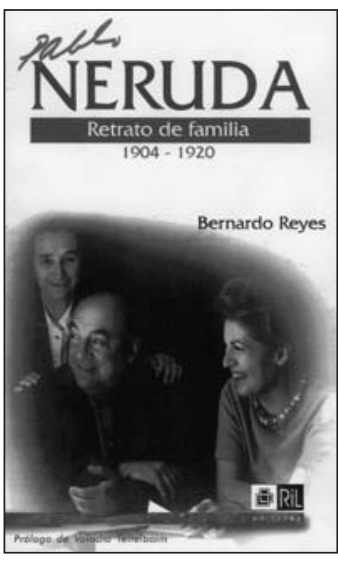

